\title{
ANEUPLOIDS AND THE CYTOGENETIC STRUCTURE OF WHEAT VARIETAL POPULATIONS
}

RALPH RILEY and GORDON KIMBER

Plant Breeding Institute, Cambridge

\section{INTRODUCTION}

Received 13.iii.6r

IT is well established that Triticum astivum $(2 n=6 x=42)$, the common wheat of agriculture, exhibits a low level of meiotic irregularity even in euploid plants of stable and agriculturally acceptable varieties. A small proportion of first metaphase cells in such varieties contains unpaired chromosomes (Thompson and Robertson, r930; Hollinshead, 1932; Riley, I960), and the frequency is much higher in heterozygous material (Person, 1956). Clearly irregularities of this nature could lead to the production of aneuploid offspring, and since many aneuploids are viable in wheat such individuals should be found in varietal populations. Hitherto, however, no evidence has been available on the occurrence of aneuploids in stocks of wheat varieties except for the speltoids and compactoids resulting from monosomy or trisomy of chromosome IX. The present paper is therefore concerned with the exploration of the significance of meiotic irregularity on the structure of wheat varieties in terms of chromosome constitutions.

\section{MATERIALS AND METHODS}

Meiotic behaviour and the frequency of plants with abnormal chromosome constitutions were scored in a number of varieties of the cultivated hexaploid wheat of commerce, Triticum aestivum L. emend. Thell. ssp. vulgare MacKey. The following varieties were involved, their origins and dates of introduction are given in brackets ; Cappelle-Desprez (Hybrid de Joncquois $\times$ Vilmorin 27, 1950), Hybrid 46 (Benoist $40 \times$ other hybrids, 1946), Holdfast (Yeoman $\times$ White Fife, 1935), Koga II ([Heines Kolben $\times$ Garnet] $\times[$ Heines Kolben $\times$ Raeckes Weissspelziger], 1953) and Atle (Extra Kolben $\times$ Saxo, 1937).

Meiosis was scored on preparations made from the spikes of at least 10 tillers collected at random in stocks of each variety. The stocks were those grown in the summer of 1959 at the National Institute of Agricultural Botany, Cambridge, from Foundation seed supplied to the Institute by the breeders of the varieties.

The frequencies of plants with irregular chromosome constitutions were determined from root-tip preparations of seedlings grown from a random sample of the seeds produced by 100 randomly sampled ears harvested from plants grown from the same Foundation seed stocks on which meiosis had been scored. Thus chromosome constitutions were scored on plants one generation removed from those grown from the Foundation seed stocks. It is a pleasure to acknowledge the help of Mr D. B. MacKay, of the National Institute of Agricultural Botany, in providing material for sampling the meiosis and chromosomal regularity of these varietal stocks.

All the plants whose root-tips showed abnormal chromosome constitutions were grown to maturity. Their chromosome constitutions were confirmed principally by meiotic examination but occasionally by checking the chromosome numbers 
of a sample of their progenies. Only those plants in which the chromosome constitution was confirmed to be abnormal are so listed in table 5 and are considered in the associated discussion.

In addition meiotic regularity was recorded in the following diploid species related to $\mathcal{T}$. aestivum, or involved in its polyploid origins :-

Triticum monococcum L. var. macedonicum Papeg. $(2 n=14)$.

Triticum boeoticum (Boiss) Scheim. ssp. aegilopoides (Link.) Schiem. $(2 n=14)$.

Aegilops squarrosa L. $(2 n=14)$.

Aegilops speltoides Tausch. var. ligustica (Savegna) Coss. $(2 n=14)$.

Aegilops longissima Schw. et Musch. $(2 n=14)$.

Univalent frequency was scored in the $\mathcal{T}$. aestivum varieties on temporary acetocarmine squashes, and in the diploid species on permanent Feulgen squashes, of pollen mother cells. Initial diagnoses of the chromosome constitutions of plants in the wheat varietal populations were made on temporary Feulgen squashes of root-tips.

\section{MEIOTIC BEHAVIOUR}

The meiotic regularity of a number of wheat varieties was scored at first metaphase of meiosis (table I). Frequencies of from 4.2 to

TABLE I

Meiotic regularity at first metaphase in five varieties of $\mathrm{T}$. aestivum

\begin{tabular}{|c|c|c|c|c|c|}
\hline Variety & & Cells & $\begin{array}{c}\text { Cells with } \\
2 \\
\text { univalents }\end{array}$ & $\begin{array}{l}\text { Per cent. } \\
\text { cells with } \\
\text { univalents }\end{array}$ & $\begin{array}{l}\text { Frequency of } \\
\text { pairing failure } \\
\text { per bivalent }\end{array}$ \\
\hline $\begin{array}{l}\text { Cappelle-Desprez } \\
\text { Hybrid } 46: \\
\text { Holdfast } \\
\text { Koga II } \\
\text { Atle }:\end{array}$ & $\begin{array}{l}\cdot \\
\dot{5} \\
\dot{5}\end{array}$ & $\begin{array}{l}500 \\
500 \\
500 \\
500 \\
500\end{array}$ & $\begin{array}{l}41 \\
28 \\
21 \\
34 \\
26\end{array}$ & $\begin{array}{l}8 \cdot 2 \\
5 \cdot 6 \\
4 \cdot 2 \\
6 \cdot 8 \\
5 \cdot 2\end{array}$ & $\begin{array}{l}0.0040 \\
0.0026 \\
0.0020 \\
0.0032 \\
0.0024\end{array}$ \\
\hline Total . & . & 2500 & 150 & $6 \cdot 0$ & 0.0028 \\
\hline
\end{tabular}

8. 2 per cent. of pollen mother cells were observed in which one pair of chromosomes had failed to make a bivalent. Since the sizes of the resulting univalents varied in different cells, the irregularities involved several distinct pairs of chromosomes. There was no possibility of determining whether the univalents resulted from asynapsis, that is lack of prophase pairing, or whether they resulted from desynapsis, that is the separation of chromosomes which had paired at prophase without chiasma-formation.

The data for the frequency of cells with univalents in all five varieties are homogeneous $\left(\chi^{2}{ }_{(5)}=8.4394, P=0.20-0 \cdot 10\right)$, consequently they may be amalgamated. The frequency of irregular cells based on the combined data is 6.0 per cent., which accords well with previous observations (Hollingshead, r932 ; Person, I956; Riley, I96o) and evidently represents a level tolerated by natural selection in this species.

The level of pairing failure in pollen mother cells of $T$. aestivum 
may be compared with that in the diploid species from which it has been derived through polyploid evolution. Meiotic regularity was recorded in Triticum monococcum and T. boeoticum-related to the donor of the A genome, in Aegilops speltoides and Aegilops longissima-related to the donor of the B genome, and in Aegilops squarrosa the D genome donor (table 2). Cells in which one pair of chromosomes were not associated in a bivalent at first metaphase were observed in all these species except $A$. squarrosa. There is a difficulty in testing the homogeneity of the ratios of regular : irregular cells since in the contingency table the expected values for cells with some pairing failure is less than 5. However, as pointed out to us by Professor K. Mather,

TABLE 2

Meiotic regularity at first metaphase of meiosis in five diploid species related to $\mathrm{T}$. aestivum

\begin{tabular}{|c|c|c|c|c|}
\hline Species & Cells & $\begin{array}{c}\text { Cells with } \\
2 \\
\text { univalents }\end{array}$ & $\begin{array}{l}\text { Per cent. cell } \\
\text { with irregular } \\
\text { cells univalents }\end{array}$ & $\begin{array}{l}\text { Frequency of } \\
\text { pairing failure } \\
\text { per bivalent }\end{array}$ \\
\hline $\begin{array}{l}\text { T. monococcum } \\
\text { T. boeoticum } \\
\text { A. squarrosa } \\
\text { A. speltoides } \\
\text { A. longissima }\end{array}$ & $\begin{array}{r}50 \\
100 \\
50 \\
100 \\
50\end{array}$ & $\begin{array}{l}2 \\
2 \\
0 \\
1 \\
\mathrm{I}\end{array}$ & $\begin{array}{l}4 \cdot 0 \\
2 \cdot 0 \\
0 \cdot 0 \\
1 \cdot 0 \\
2 \cdot 0\end{array}$ & $\begin{array}{l}0 \cdot 0057 \\
0.0028 \\
0 \cdot 0000 \\
0 \cdot 0014 \\
0 \cdot 0028\end{array}$ \\
\hline Total & $35^{\circ}$ & 6 & I. 7 & $0 \cdot 0026$ \\
\hline
\end{tabular}

this should lead to a spuriously high $\chi^{2}$ value in such a test. Consequently, since $\chi^{2}{ }_{(5)}=2.9385, \mathrm{P}=0.8-0.7$, the data for all diploids can be accepted as homogeneous and may therefore be amalgamated.

In the combined data for the diploid species the frequency of irregular cells was $1 \cdot 7$ per cent. which is considerably less than that observed in $T$. aestivum. Indeed there is a significant difference in the ratios of regular : irregular cells in $T$. aestivum and in its diploid ancestors $\left(\chi_{(1)}^{2}=\mathrm{II} \cdot 3982, \mathrm{P}=<0 \cdot 001\right)$.

When, however, the data are expressed as the ratios of pairs as bivalents : pairs as univalents there is no significant difference between the diploids and the hexaploid $\left(\chi^{2}{ }_{(1)}=\mathrm{I} \cdot 5885, \mathrm{P}=0 \cdot 30-0 \cdot 20\right)$. The overall frequency of bivalent failure per chromosome pair was 0.0028 in $T$. aestivum and 0.0026 in its diploid ancestors. There was thus little difference in the probability of a pair of chromosomes failing to form a bivalent, the greater frequency of irregular cells in the hexaploid merely resulting from the greater number of chromosomes with pairing properties like those of the diploids.

\section{MONOSOMICS AND TRISOMICS}

The irregular first metaphase cells which occur with low frequencies in the diploid ancestors of wheat are unlikely to influence population structures since it is improbable that the aneuploid individuals, to 
which they might give rise, would be viable at this chromosome level. This is not true, however, of the similar irregularities in $T$. aestivum, in which plants nullisomic, monosomic, trisomic and tetrasomic for each of the 2 I chromosomes are known to be viable (Sears, I954).

Considerable information is available, on the transmission of the univalent chromosomes in wheat monosomics, which can be applied to predict the behaviour of unpaired chromosomes in euploid plants (Morrison, 1953; Sears, 1953, 1954). In monosomics the univalent is transmitted to about 25 per cent. of the gametes and is omitted from about 75 per cent. Functional embryo sacs with 2 I and 20 chromosomes have been shown to occur in approximately these frequencies when monosomic individuals are pollinated by euploids.

Morrison (1953) has shown that about 68 per cent. of the pollen grains of monosomics have 20 chromosomes and 30 per cent. have 2 I chromosomes. However, as a result of competition between the two classes, 96 per cent. of the pollen which is successful in fertilisation has 2 I chromosomes and only four per cent. has 20 chromosomes.

These frequencies of segregation and transmission of the univalent mean that self-pollination of monosomics typically produces about 24 per cent. of 42 -chromosome euploids, 73 per cent. of $4 \mathrm{I}$-chromosome monosomics and 3 per cent. of 40-chromosome nullisomics. These transmission frequencies were first illustrated by Sears (1953) in the way depicted in table 3 .

If the univalents in euploid cells with 20 bivalents and 2 univalents are transmitted independently, and each in the same frequency as the single univalent in monosomics, then 20-, $2 \mathrm{I}$ - and 22-chromosomes gametes will be formed in the ratio $9: 6: \mathrm{I}$. Thus, if the frequency of first metaphase cells with two univalents is 0.06 as observed here (table I), the overall frequency of 20-chromosome gametes will be $\frac{9}{16} \times 0.06=0.0337$. The meiotic observations were based on pollen mother cells, but it is unlikely that any chromosome-deficient pollen grains will succeed in fertilisation in competition with a large excess of euploid grains. Consequently chromosome elimination is only likely to occur as a result of irregular meiosis in megaspore mother cells. If the data for pollen mother cell irregularities are assumed to apply to megaspore mother cells then 20-chromosome egg cells will be produced with a frequency of 0.0337 . Assuming that only $2 \mathrm{I}-$ chromosome pollen functions, $4 \mathrm{I}$-chromosome monosomics will arise in the progeny of euploids with the same frequency.

However, the monosomics will reproduce themselves giving frequencies of 0.73 monosomics, 0.24 euploids and 0.03 nullisomics in their progenies (table 3). If these premises are correct, and if there is no differential reproductive capacity of monosomics compared with euploids, a model can be made which describes the frequency of monosomics in populations under various conditions.

Thus if $a$ is the frequency of monosomics in the progeny of euploids, then in a population obtained entirely from euploid parents $a$ would 
also be the frequency of monosomics in the population. In the next generation a proportion $(r)$ of the progeny of the original monosomics would again be monosomic, and monosomics would again have newly originated from euploids with a frequency $a$. Consequently the overall frequency of monosomics would be $a+r a$. Similarly in the third generation the frequency would be $a+r a+r(r a)$. The frequency of monosomics can thus be expressed as a geometrical progression of which the first term is the new production of monosomics from euploids (a) and the common ratio $(r)$ is the proportion of monosomics in the progenies of monosomics. In the conditions described for T. aestivum, $a=0.0337$ and $r=0.73$.

TABLE 3

Typical transmission of the monosomic condition in $\mathrm{T}$. aestivum (after Sears, 1953)

\begin{tabular}{|c|c|c|}
\hline$\rho$ & $\begin{array}{c}\text { 2 I-chromosome } \\
\text { pollen } \\
0.96\end{array}$ & $\begin{array}{c}\text { 20-chromosome } \\
\text { pollen } \\
0.04\end{array}$ \\
\hline $\begin{array}{c}2 \text { I-chromosome eggs } \\
0.25\end{array}$ & $\begin{array}{l}2 \mathrm{I}^{\prime \prime} \text { plants } \\
0 \cdot 24\end{array}$ & $\begin{array}{l}20^{\prime \prime} \mathrm{I}^{\prime} \text { plants } \\
\mathrm{O} \cdot 0 \mathrm{I}\end{array}$ \\
\hline $\begin{array}{l}\text { 20-chromosome eggs } \\
0.75\end{array}$ & $\begin{array}{l}20^{\prime \prime} \mathrm{I}^{\prime} \text { plants } \\
0.72\end{array}$ & $\begin{array}{l}20^{\prime \prime} \text { plants } \\
0 \cdot 03\end{array}$ \\
\hline
\end{tabular}

euploids $\left(2 \mathrm{I}^{\prime \prime}\right)=0.24$

monosomics $\left(20^{\prime \prime} \mathrm{I}^{\prime}\right)=0.73$

nullisomics $\left(20^{\prime \prime}\right)=0.03$

Since the common ratio is less than unity the geometrical progression can be summed to infinity using the formula, $S \infty=\frac{a}{\mathrm{I}-r}$. The sum to infinity will be equal to the frequency of monosomics in an old established and stabilised population. In the present case $S \infty=\frac{0 \cdot 0337}{\mathrm{I}-0^{\cdot} 73}=0 \cdot 1248$, which is the estimated frequency of monosomics.

The expected frequency of trisomics in a wheat population can be similarly calculated. One-sixteenth of the gametes produced from meiotic cells with 20 bivalents and two univalents should have 22 chromosomes, if the segregation is at random. Consequently, if 0.06 is the frequency of irregular meiotic cells the total frequency of 22chromosome gametes should be $\frac{1}{16} \times 0.06=0.00375$. This is also the frequency with which trisomics should arise from euploids, assuming that only euploid pollen functions due to competition, and that irregular meiosis in megaspore mother cells is at the same rate as in pollen mother cells. Moreover trisomics occur in the progenies of trisomics with a frequency of the order of 0.414 , table 4 (Sears, 1954). 
In the geometrical progression representing the expected frequency of trisomics, therefore, $a=0.00375$ and $r=0.414$. Consequently, $S \infty=\frac{0.00375}{\mathrm{I}-0.4{ }^{\mathrm{I}} 4}=0.00639$, which is the expected frequency in a stable population.

To test the predicted frequencies of aneuploids, the chromosome constitutions were scored of 2027 seedlings of four wheat varieties (table 5). There was a total of 14 monosomics and 3 trisomics, so that the respective frequencies were 0.0069 monosomics and 0.00148 trisomics. Clearly there is a great difference between the expected and the observed frequencies of these two aneuploid classes.

TABLE 4

Typical transmission of the trisomic condition in $\mathrm{T}$. aestivum ( from the data of Sears, 1954)

\begin{tabular}{|c|c|c|}
\hline$q$ & $\begin{array}{c}2 \text { I -chromosome } \\
\text { pollen } \\
0.93\end{array}$ & $\begin{array}{c}\text { 22-chromosome } \\
\text { pollen } \\
0 \cdot 07\end{array}$ \\
\hline $\begin{array}{c}21 \text {-chromosome eggs } \\
0.60\end{array}$ & $\begin{array}{l}2 \mathrm{I}^{\prime \prime} \text { plants } \\
0.55^{8}\end{array}$ & $\begin{array}{l}20^{\prime \prime} \mathrm{I}^{\prime \prime \prime} \text { plants } \\
0 \cdot 042\end{array}$ \\
\hline $\begin{array}{l}\text { 22-chromosome eggs } \\
0.40\end{array}$ & $\begin{array}{l}20^{\prime \prime} I^{\prime \prime \prime} \text { plants } \\
0 \cdot 372\end{array}$ & $\begin{array}{l}20^{\prime \prime} \mathrm{I}^{\prime \prime \prime \prime} \text { plants } \\
0.028\end{array}$ \\
\hline
\end{tabular}

euploids $\left(2 \mathrm{I}^{\prime \prime}\right)=0.55^{8}$

trisomics $\left(20^{\prime \prime} I^{\prime \prime \prime}\right)=0.414$

tetrasomics $\left(2 \mathrm{O}^{\prime \prime} \mathrm{I}^{\prime \prime \prime}\right)=0.028$

However, if the assumptions about the transmission of the univalent chromosomes in euploids and aneuploids are accepted, the formulae for the geometrical progressions can be recalculated to give estimates of $a$, the new production of aneuploids from euploids in each generation. Thus, dealing with monosomics, the sum to infinity of the series is known as the determined frequency in the population checked, that is 0.0069 , and the common ratio, 0.73 , is established from the known behaviour of monosomics. Therefore, $S \infty=\frac{a}{1-r}$ can be expressed as $0 \cdot 0069=\frac{a}{\mathrm{I}-0 \cdot 73}$, consequently $a=0 \cdot 001863$.

Thus, on the observed population frequency of monosomics, $0 \cdot 1863$ per cent. of the progeny of euploids should be monosomic. When the chromosome numbers were checked of 200 plants in the progenies of euploid plants, in the variety Holdfast, one monosomic was found. Although a considerably larger sample would need to be examined to check the predicted production of monosomics, it may well be that the estimate is reasonably correct.

Similarly the production of trisomics from euploids can be estimated 


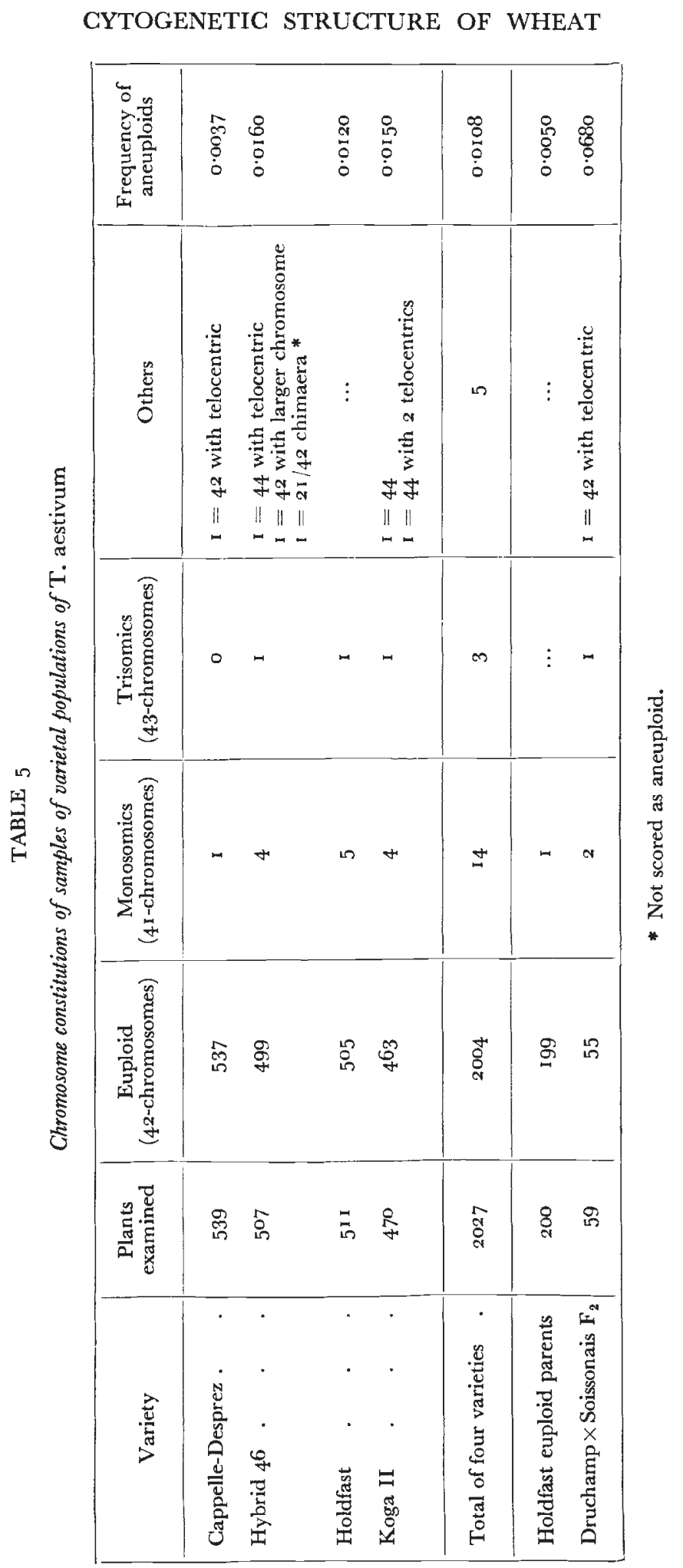


from the observed frequency of trisomics in the population. This was 0.00148 and again equals the sum to infinity of the geometrical progression. Consequently when $S \infty=\frac{a}{\mathrm{I}-r}$ and $r=0.414,0.00148=$ $\frac{a}{\mathrm{I}-0.4^{\mathrm{I}} 4}$, and $a=0.000867$.

Thus 0.0867 per cent. of the progeny of euploid wheat plants should be trisomic.

The causes may now be considered of the errors in the estimated occurrences of monosomics and trisomics, in varietal populations, based on the observed frequencies of first metaphase irregularities. It should be indicated at the outset that no information is available to show how closely the populations sampled resembled stabilised populations. Those examined were derived from Foundation seed of established varieties which was produced by the breeders of the varieties. In building the Foundation stocks the breeders may well have exercised selection, against rogues, which would have reduced the proportion of aneuploids.

If, however, as seems probable, this was not solely responsible for the deficiency of aneuploids, three others factors should be considered. These are the assumptions that:-

(a) There is no difference in the reproductive efficiency of monosomics and trisomics compared with euploids.

(b) The two univalents in euploids segregate at random.

(c) The frequency of irregular first metaphase in megaspore mother cells is the same as that in pollen mother cells.

General experience with monosomics and trisomics in wheat suggests that they are usually as efficient in reproduction as euploids. However, even if the fertility of monosomics was reduced, for example, to 90 per cent. of that of euploids, the frequency of monosomics would be $S \infty=\frac{0.0337}{\mathrm{I}-(0.73 \times 0.90)}=0.0982$. Similarly the frequency with 50 per cent. fertility would be 0.05937 . These values, and others similarly calculated for trisomics, are still greatly in excess of the observed frequencies, so that it seems unlikely that differential fertility can be an important factor in causing the discrepancy between the observed and predicted frequencies of aneuploids.

In wheat monosomics the univalent chromosome usually divides into chromatid-halves at first anaphase of meiosis and may then be included or excluded after second anaphase movements. However, chromosomes which have paired at prophase without chiasmaformation sometimes remain secondarily associated as univalents (Person, 1955; Riley and Chapman, 1957). Occasionally the secondarily associated univalents then orientate on the first metaphase plate and separate one to each pole in late anaphase. If the two 
homologous univalents in irregular euploid cells often separated in this way, predictions based on the behaviour of univalents in monosomics would be erroneous. However, observation of the irregular cells of euploids suggests that the univalents rarely co-orientate in this way and that the behaviour of the two univalents is generally independent. Consequently non-random segregation of univalents is unlikely to be a source of error in estimating the frequencies of monosomics and trisomics in populations.

The remaining possibility of error lies in the assumption that pairing failure occurs in megaspore mother cells in the same frequency as in pollen mother cells. Meiosis has apparently never been studied in megaspore mother cells in wheat. Indeed it would be extremely difficult to assemble a sample of adequate size to determine the level of meiotic regularity. However, it might be expected that meiotic irregularity would be less common than in pollen mother cells. For each ovary in wheat produces only one embryo sac and one seed, consequently every megaspore meiosis influences fertility and any inefficiency in the meiotic process would immediately diminish the reproductive effectiveness of an organism selected for a high yield of seeds. By contrast a small proportion of cytologically unbalancedpollen grains would not influence fertility in a self-fertilising plant in which most of the pollen produced is wasted. Therefore the selection pressures acting to produce meiotic regularity are probably more stringent in their impact on megaspore mother cells than on pollen mother cells. Thus a higher level of pairing failure might well be tolerated at meiosis in pollen mother cells. The discrepancy between the frequencies of irregular pollen mother cells and the observed frequencies of aneuploids, which arise from irregular megaspore meiosis, could well be a manifestation of the different courses of division in the two types of cells.

Indeed, using the estimated frequencies of the origin of monosomics and trisomics from euploids, which were derived from the observed occurrences of these aneuploids in populations, further estimates can be made of the frequencies of irregular megaspore mother cells. If the frequency of the production of monosomics from euploids is $0 \cdot 001863$, then the frequency of irregular megaspore mother cells from which they arise must be 0 . oor $863 \times \frac{16}{9}=0.003301$. A similar calculation, based on the frequency of trisomics, gives an estimate of $0 \cdot 000914 \times 16=0.013872$.

Thus a bivalent is estimated to have failed in $0.330 \mathrm{I}$ or in 1.3872 per cent. of megaspore mother cells on the basis of the observed occurrence of monosomics or trisomics respectively. The differences between these estimates may result from differences between the viabilities of trisomics and monosomics, or between the gametes from which they are derived. Alternatively some of the excess of trisomics in the population studied may have resulted from the decay of the tetrasomic condition through segregation. Finally the difference 
may merely be due to sampling errors in the observations of aneuploid frequencies in the population studied. Irrespective of the cause of the difference, however, it seems that there must be a marked reduction in the occurrence of irregularities at meiosis in megaspore mother, compared with pollen mother, cells.

\section{OTHER ANEUPLOIDS}

Monosomics and trisomics can of course give rise by segregation respectively to nullisomics and tetrasomics. Nullisomics in wheat are of low vigour and are usually either completely sterile or very infertile. Consequently nullisomics would probably be quickly eliminated from the population. Indeed any present in the population would probably have been newly derived from a monosomic parent. On the basis of the 2027 seedlings checked (table 5) 0.69 per cent. of the population proved to be monosomic. With this population frequency of monosomics, and assuming that 3 per cent. of the progeny of monosomics are nullisomics (table 3 ), then o.or 3 per cent. of the varietal population should consist of newly arisen nullisomics. None was discovered in the varieties examined but the sample was rather small for the detection of such a minor component of the population.

By contrast with nullisomics, tetrasomics are viable and fertile and are partially stable. Tetrasomics for most chromosomes produce about 80 per cent. tetrasomics in their progenies. Consequently, although they are produced from trisomics with only about the same frequency as nullisomics from monosomics, once they have arisen they will form a persistent component of the population. It is not surprising, therefore, that three tetrasomics were observed amongst the 2027 seedling examined (table 5 ).

Most of the non-tetrasomic progeny of tetrasomics are trisomic. Thus the tetrasomic component of a varietal population will represent a source of inflation of the proportion of trisomics.

The univalent chromosomes in euploids and monosomics or in those trisomic cells in which no trivalent is formed, may occasionally misdivide at meiosis to give rise to telocentrics or isochromosomes. In the present work no isochromosomes were observed presumably because plants with aberrant chromosome conditions were selected from the examination of somatic chromosomes and isochromosomes would be indistinguishable from a number of normal chromosomes with median centromeres. However three plants were obtained with telocentric chromosomes. Two of these had tetrasomic numbers and one had a euploid number (table 5 ).

Clearly misdivision of this nature can lead to the inclusion of stable chromosomal off-types in a variety. Thus for example the 42-chromosome plant with one telocentric found in Cappelle-Desprez could segregate to form 42-chromosome offspring disomic for the telocentric condition. Unless selectively eliminated these would then form persistent cytological deviants in the population. 


\section{CONCLUSIONS}

\section{(i) The population structure of wheat varieties}

From the present work it is apparent that there is a small component of varietal populations of $T$. aestivum continuously moving through aneuploid conditions. Aneuploids arise from the euploid condition and slowly over several generations most of the derivatives of the initial aneuploids revert to euploid. This slow turn-over of aneuploids depends upon the presence of considerable genetic duplication associated with a diploid-like meiotic pattern in which bivalent formation occasionally fails. The bivalent failure may arise from the combination of the chromosome sets of three diploid species which also occasionally form univalents. However, there seems to be little deleterious effect, since most aneuploid conditions do not disturb the fertility or the vigour of wheat. The only components of the population permanently modified arise through the effective fixation of tetrasomy and through the accumulation of misdivision products.

It may be assumed that all chromosomes are equally likely to fail to pair at meiosis in euploids, and to give rise to aneuploidy. However, there is as yet no direct evidence on this, although the differences in plant morphology between some of the aneuploids extracted (plate I) give some confirmation.

The extent of genetic duplication is sufficiently great in Triticum aestivum for considerable laxity in the control of chromosome organisation to be tolerated. Indeed it may be that the passage of chromosomes through the monosomic phase promotes the retention of much duplication. Since the least deviation from the euploid phenotype, which is presumably the optimum expression, will occur in those plants efficiently buffered by duplications. Thus selection for masking duplications may occur.

It is noteworthy that the exposure of parts of the genotype to the hemizygous condition is only likely to be tolerated in an inbred, and largely homozygous, organism such as wheat. In an outbreeder monosomics would probably expose deleterious recessive genes and so would reduce the overall efficiency of the population. Consequently selection would operate against a meiotic system which caused the production of aneuploids. Under these conditions it is perhaps surprising that genes which are ineffective when hemizygous, such as the speltoid suppressor $(Q)$ on chromosome IX, are not uncommon in wheat (Sears, 1954), since monosomy for a chromosome carrying such a gene must be immediately apparent.

Paradoxically also, the genetic deviation which results from the production of monosomics may also lead to a return to even greater stability. For the euploids derived from monosomics will be completely homozygous in the homologues which have passed through the monosomic phase. In the generations immediately following hybridisation, when the frequency of monosomics is considerably 
higher than in stabilised varieties (table 4), this may have some selective advantage in speeding the return to homozygosity. In established varieties passage through the monosomic condition will also remove heterozygosity from chromosomes carrying newly arisen mutants.

Thus the dynamic state of the chromosome composition of wheat populations seems to lead to only minor adverse effects and may indeed confer certain selective advantages. The production of aneuploids and their reversion to euploidy may merely be the fortuitous outcome of the continuation in the polyploid of the bivalent failure which occurs in its diploid ancestors. At the polyploid level however, due to duplications, the individuals with irregular chromosome constitutions, to which the pairing failure inevitably gives rise, are viable.

\section{(ii) The genetic purity of wheat varieties}

In many countries organisations exist to ensure that pure stocks of seeds of many crops, including wheat, are available to the farmer. There can be no doubt of the great value of this service in ensuring that the varieties distributed are those named, and that stocks are not mixed with the seeds of other varieties. In addition it is obviously important to be sure that there is no undue contamination with seed borne diseases or with the seeds of weed species. However, it is sometimes also the task of such organisations to ascertain that the genetic variation in the crop is minimal, and to this end standards of genetic purity are set.

It has been the purpose of this paper to demonstrate that a fairly high level of chromosomal irregularity is inevitable in the wheat crop. In the varieties examined plants with irregular chromosome constitutions ranged from 0.37 per cent. to $\mathrm{I} \cdot 60$ per cent. of those examined, with a mean of $\mathrm{I} \cdot 08$ per cent. (table 5 ). (In the oat variety Sun II, I. Io per cent. of the $63 \mathrm{I}$ plants examined were aneuploid.) These are frequencies much greater than those tolerated for morphologically distinguishable "off-types" by some seed certifying organisations. Consequently, in as much as irregular chromosome constitutions may lead to phenotypic deviations from the standard type, it may be that biologically impossible targets are set.

The most common class of irregularity in wheat arises from the occurrence of monosomics. Wheat varieties differ in the phenotypic effect of the monosomic condition. This can be illustrated from the difference between Chinese Spring and Holdfast neither of which, it should be indicated, are now commercial varieties. Whereas in Chinese Spring none of the monosomics, except that for chromosome IX, differs phenotypically from the euploid under favourable conditions, in the variety Holdfast many different monosomics cause distinctive modifications of the phenotype (plate I). This, rather than real differences in genetic behaviour, may be the cause of observations commonly made by agronomists that some wheat varieties are more 


\section{Plate}

Mature plants, and ripe ears from the same plants, from the sample of the variety Holdfast checked for chromosome constitution, $(a)$ and $(e) 4^{2-c h r o m o s o m e ~ e u p l o i d ; ~}(b)$ and $(f),(c)$ and $(g),(d)$ and $(h) 4^{\mathrm{I} \text {-chromosome monosomics. }}$ 


$$
\begin{aligned}
& \text { - } 21722222250 \\
& \text { - } \\
& 15202025000 \\
& \text { - }
\end{aligned}
$$
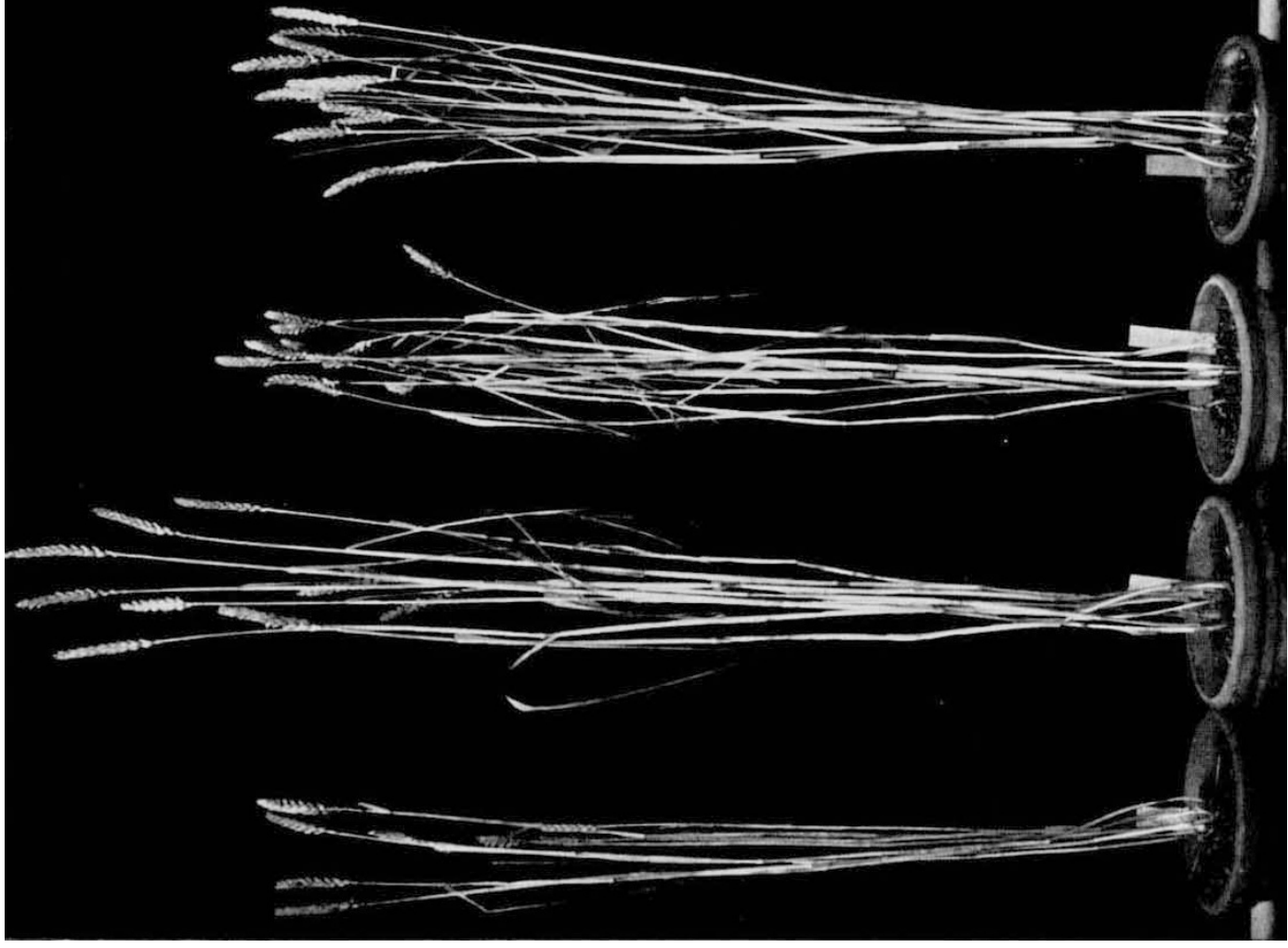
constant than others. However, it is clear that in a variety with many distinguishable monosomics, the level of genetic impurity permitted should be relaxed compared with some other varieties. It must be recognised that this assumes a high ascertainment of morphological deviants, whereas under field conditions some of the aneuploid deviants would probably fall within the range of environmentally-caused variation of the euploid majority of the crop. Nevertheless the standards of genetic purity demanded should be so devised that they fit a level realisable in the crop.

It has been indicated earlier that the initial aneuploid states may lead to the fixation of tetrasomic or of misdivision conditions, in the latter case as disomic telocentric plants with euploid numbers. The tetrasomics for most chromosomes are recognisably different in morphology from the standard type (Sears, 1954), and most disomic telocentrics deviate from normal in the direction of the corresponding nullisomic. The probability of the accumulation of these aberrant, and inefficient, classes in unselected stocks of a wheat variety must emphasise the importance of the continued return to selected stocks, and must stress the importance to agriculture of supplies of pure seeds. The only conern is that, in attempting to obtain genetically standardised seed supplies, a level of purity should not be demanded which the meiotic system of the plant does not permit.

(iii) Spontaneous aneuploids and wheat breeding

Person (1956) has pointed out that the level of meiotic irregularity, particularly pairing failure, is much higher in heterozygous wheat material than in stable, more or less homozygous, varieties. Indeed he has demonstrated that, from the $F_{1}$ and through the succeeding backcross generations, the return to the normal level of pairing failure follows the return to homozygosity.

It might be anticipated, therefore, that the production of aneuploids would be greater in the early generations following an intervarietal hybridisation than in a normal variety. Consequently the chromosome numbers were counted of $59 \mathrm{~F}_{2}$ seedlings from an intervarietal hybrid between Druchamp and Soissonais. Of these 55 had 42 normal chromosomes, one had 42 chromosomes including a telocentric, two were monosomic and one was trisomic. There was thus an aneuploid frequency of 6.8 per cent., which is much higher than the frequency found in any of the varieties studied. The greater pairing failure observed by Person in heterozygous material is probably directly reflected in a greater production of aneuploids.

It is of interest that wheat, an inbreeder, apparently shows increased meiotic irregularity on outbreeding whereas rye, an outbreeder, shows increased irregularity on inbreeding (Rees, 1955). The stability of meiosis presumably depends, therefore, upon balanced genetical systems comparable with those demanded for the stable development of other characters (Jinks and Mather, 1955). 
The return to homozygosity following intervarietal hybridisation in wheat will be hastened by the greater failure of pairing and aneuploid production in heterozygous material. In the euploids derived from early generation monosomics the chromosome pair which had passed through the monosomic phase will be homozygous. Moreover the failure of meiotic pairing must diminish the anticipated amount of recombination in wheat hybrids.

These are considerations which may be relevant in the organisation of wheat hybridisation programmes. Thus, because of pairing failure and monosomic production, some chromosomes must be transferred unaltered from one parent into the derived breeding material. This means that some wheat hybridisation programmes involve the unconscious use of procedures somewhat similar to the intervarietal chromosome substitution methods developed by Sears, Loegering and Rodenhiser (1957) and Unrau (1958). However, instead of a chromosome being transferred unaltered from one variety to another, an unmodified chromosome will be transferred from one variety into new genotypes resulting from the recombination and segregation of the rest of the complement. The presumed occurrence of this process draws attention to the complete lack of information, in wheat breeding, on the relative significance of intra-chromosomal recombination and inter-chromosomal segregation.

\section{(iv) Extraction of monosomic series}

Significant cytogenetic information has been obtained in wheat from manipulations based on aneuploids. The most extensive work has involved the use of the complete series of 2 I monosomic lines originally developed in the variety Chinese Spring by Sears (I953). From this original series full sets of monosomics have been produced in other varieties by backcrossing (Unrau, I958).

The first series of monosomics was extracted from the derivatives of two Chinese Spring haploids and from various Chinese Spring-rye combinations. However, it is clear that given sufficient effort it might well be possible to assemble a series of monosomics in any wheat variety simply by collecting those which occur spontaneously.

This is no longer necessary in $T$. aestivum since it is probably easier to transfer the monosomic condition from one variety to another by backcrossing. Nevertheless the extraction of a monosomic set by selecting spontaneous monosomics might be possible in other species having similar cytogenetic compositions. Such a species is the hexaploid cultivated oat of commerce, Avena sativa $(2 n=42)$, which has a diploid-like meiotic process in which $2 \mathrm{I}$ bivalents are formed. However, its meiosis is not completely regular and, as in wheat, single pairs of chromosomes occasionally fail to form bivalents (Joshi and Howard, 1955).

The consequence of this irregularity should be the formation of aneuploids, as in wheat. To check this the chromosome numbers 
were counted of 631 seedlings of the variety Sun II. Of these 623 had 42 chromosomes, seven had 4 I chromosomes and one had 34 chromosomes. The chromosome constitutions of the aneuploids were confirmed at meiosis. It thus appears that the assembly of spontaneous monosomics should be possible. The results accruing from the production of a monosomic series in oats might well be as significant in terms of cytogenetic information, and as valuable in relation to practical breeding techniques, as have been those obtained in wheat.

\section{SUMMARY}

I. Aneuploids are produced in the progenies of euploid individuals of common wheat, Triticum aestivum, due to occasional pairing failure at meiosis.

2. Data are available on the behaviour of univalent chromosomes and on the inheritance of aneuploid conditions in wheat. Consequently it is possible to determine the significance of an euploidy for the structures of varietal populations.

3. The initial aneuploids-monosomics or trisomics-produce progenies which include euploid plants as well as plants with the parental chromosome constitution. After several generations most of the derivatives of a monosomic or trisomic will have reverted to euploid. Thus there is a slow turn-over of the aneuploid fraction of the population.

4. A small proportion of aneuploids becomes fixed in the population through the production of tetrasomics from trisomics and through the production of plants homozygous for misdivision conditions.

5. From the formulae calculated to describe the population structures it can be concluded that pairing failure occurs less often in megaspore mother cells than in pollen mother cells of euploid plants.

6. The overall frequency of aneuploids in the varieties examined was 1.08 per cent. of the population. This is sufficiently high to merit consideration in the establishment of the standards of genetic purity required in seed stocks of wheat.

Acknowledgments.-Thanks are due to $\mathrm{Mr}$ T. E. Miller for help in the production and examination of preparations of somatic chromosomes, and to Mr H. A. Torrens for other technical assistance.

\section{REFERENCES}

HOLlingsheAd, L. I932. The occurrence of unpaired chromosomes in hybrids, between varieties of Triticum vulgare. Cytologia, 3, I I 9-141.

JINKs, J. L., AND MATHER, K. 1955. Stability in development of heterozygotes and homozygotes. Proc. roy. Soc. B, I43, 56 I-578.

JOSHI, A. B., AND HOWARD, H. W. I955. Meiotic irregularities in hexaploid oats. III. Further observations on the frequency of univalents and other meiotic irregularities in Spring $\times$ Winter variety hybrids of Avena sativa. 7. agric. Sci., $45,380-387$. 
Morrison, J. W. I953. Chromosome behaviour in wheat monosomics. Heredity, $7,203-217$.

PERSON, C. 1955. An analytical study of chromosome behaviour in a wheat haploid. Canad. 7. Bot., 33, I I-30.

PERSON, c. I956. Some aspects of monosomic wheat breeding. Canad. F. Bot., $34,60-70$.

REES, H. 1955. Genotypic control of chromosome behaviour in rye. I. Inbred lines. Heredity, 9, 93-1 I 6 .

RILEY, R. I96o. The meiotic behaviour, fertility and stability of wheat-rye chromosome addition lines. Heredity, I4, 89-100.

RILEY, R., AND CHAPMAN, v. 1957. Haploids and polyhaploids in Aegilops and Triticum. Heredity, II, I95-207.

SEARS, E. R. I953. Nullisomic analysis in common wheat. Amer. Nat., 87, 245-252. SEARS, E. R. I954. The aneuploids of common wheat. Res. Bull. Mo. Agric. Sta., 472.

SEARS, E. R., LOEGERING, W. Q., AND RODENHISER, H. A. 1957. Identification of chromosomes carrying genes for stem rust resistance in four varieties of wheat. Agron. 7., 49, 208-212.

THOMPSON, W., AND ROBERTSON, H. T. r930. Cytological irregularities between species of wheat with the same chromosome number. Cytologia, I, 252-262.

unrau, J. 1958. Survey of work with monosomics in Canada. Proc. First Int. Wheat Genet. Symp., 230-236. 